\title{
Short communication \\ The case for user involvement in research: the research priorities of cancer patients
}

\author{
David NM Wright ${ }^{1}$, Jessica L Corner ${ }^{2}$, Jane B Hopkinson ${ }^{1}$ and Claire L Foster ${ }^{1}$
}

${ }^{1}$ Macmillan Research Unit, School of Nursing and Midwifery, University of Southampton, Highfield, Southampton, SO17 1BJ, UK
${ }^{2}$ School of Nursing and Midwifery, University of Southampton, Highfield, Southampton, SO17 1BJ, UK

Corresponding author: David NM Wright, dnmw@soton.ac.uk

Published: 20 December 2007

This article is online at http://breast-cancer-research.com/content/9/S2/S3

(C) 2007 BioMed Central Ltd

\section{Introduction}

User involvement in health research has increased in influence in recent years. (The definition of 'user' is contentious. The term does not solely include patients and their carers, but may also include members of the general public, potential patients and public, community and voluntary organizations and health professionals. This paper uses this broader definition of the term.) Involving users in research activity inevitably challenges the traditional autonomy of expert clinicians or academics in the research process. Consequently, attitudes to user involvement are typically polarized, either perceiving such involvement as a universal panacea or as a malevolent force that jeopardizes research practice. This paper moves beyond simplistic characterizations of user involvement to consider the benefits of engaging users in research and reflects on commonly asserted criticisms of such activity. Findings from a recently completed research prioritization exercise, the Macmillan Listening Study, will be cited to justify the need to involve users in research [1].

\section{Drivers for user involvement}

There are numerous drivers for user involvement in research.

\section{The political imperative}

Publications such as the Department of Health's Research Governance Framework [2] identify user involvement as a key component of good research practice: 'Relevant service users and carers or their representative groups should be involved wherever possible in the design, conduct, analysis and reporting of research.'

\section{The ethical dimension}

User involvement is seen to be important in maintaining ethical standards and the welfare of participants in research. Consequently, questions concerning user involvement are now a standard part of all UK National Health Service Research Ethics Committee forms, regardless of the type of research.
Breast Cancer Research 2007, 9(Suppl 2):S3 (doi:10.1186/bcr1801)

\section{Patient advocacy}

Many view involvement in research to be a democratic right of service users. The growth of patient advocacy groups, such as the National Breast Cancer Coalition in the USA, has contributed to the increased demand for users to be involved in research as a fundamental right.

\section{The academic community}

The academic community is increasingly reporting the benefits of involving users in research $[3,4]$. Hence, user involvement is seen to be important in improving the relevance and utility of research.

\section{Users as citizens}

It has been suggested that user involvement is derived from a consumerist agenda, one that applies the concept of market forces to health research and service provision. Thus, patients have freedom of choice concerning which services to use and how studies should be conducted [5]. This consumerist agenda has been criticized by those who suggest that not all service users wish to make choices and that certain individuals are more able to make choices than others [6]. However, the concept of the user as consumer has been superseded by an understanding of their citizenship role. In particular, advocates of participatory research argue that users should be viewed as active citizens in the research process $[7,8]$. User involvement thus becomes a question of democratic right rather than market choice.

\section{Benefits of user involvement}

There are many benefits of involving users in research. First, users offer a different perspective from that of clinicians and academics, one that is based on their own unique experiences of living with illness [2]. Hence, engaging with users ensures that the outcomes of research are not just those that are considered important by academics or clinicians. Second, users can use their experiences to ensure that research reflects the interests of the general public and thus health 
and social services designed to support users. Third, users can assist in focusing research activity on areas of interest, relevance and benefit to people affected by various conditions [9]. Fourth, users can facilitate recruitment into research by improving the design of patient information sheets, the consent process and the appropriateness of recruitment procedures [9]. This is particularly important when recruiting participants from marginalized communities, such as diverse ethnic minorities, in which community representatives can be instrumental in enhancing the cultural relevance of research design [10]. Fifth, users can enhance data collection, particularly in research involving ethnic minorities, where they can improve access to research information [10]. Finally, user involvement can improve the dissemination and implementation of study findings, ensuring they are presented in formats that are accessible to a wider audience [9].

\section{Addressing criticisms of public involvement}

The following criticisms have also been made concerning user involvement: Users involved in research are not representative of all service users. The degree to which users are representative is further compromised by a tendency for health professionals to select patients who are 'well behaved' and thus support their interests. Users become 'professionalized' over time, thus undermining their representativeness. Research is a complicated exercise that requires skills that cannot quickly be learned and utilized by users. Patient confidentiality can be compromised if users have access to patient data obtained during the course of a study. Users are inevitably close to their own experiences of disease, and therefore they lack objectivity, thus potentially skewing study findings. Users do not understand the complexities of the research process, such as funding or ethics, and hence they may have unrealistic expectations. User involvement is costly and can generate unnecessary delays. Users are only interested in short-term problems rather than longer term considerations. Clinicians and academics already serve and reflect the interests of users. Finally, there is no evidence that user involvement improves the conduct of research.

Many of the concerns raised are not specific to user involvement but are relevant to the conduct of research in general. Questions about representativeness, confidentiality, objectivity and aptitude are relevant to all researchers, whether they are patients or clinicians. These concerns are resolved by considering how users are identified, the nature of the tasks they undertake, and how their unique expertise can be accessed through appropriate training and support $[3,11]$.

Other concerns, such as the selection of 'well behaved' users, the expectations of users, time delays and the focus on short-term concerns are again not valid criticisms of user involvement. Rather, they are examples of problems associated with poor practice in user involvement. The careful selection and identification of users will resolve problems associated with 'well behaved users'. Involving the public early in the research process will minimize delays experienced during the course of the study. Attention to study design and ensuring that users are informed of the aims of the study will ensure that patients and carers are not preoccupied with 'short-term' concerns. The issue of financial cost is important, although numerous forms and levels of user involvement exist, from steering committee representation to user-led research [12]. Hence, users can be involved in ways that are appropriate to study aims and funding level.

The criticism that clinicians and academics already serve the interests of users is a reflection of their personal beliefs regarding user involvement and their own role in the research process. Finally, there is growing evidence of the benefits of involving users in research [3,4]. Although much of this evidence is anecdotal, organizations such as INVOLVE are increasingly collating information on the impact of users on research [13].

\section{The need to involve users: the Macmillan Listening Study}

Research governance and ethics guidelines can inadvertently promote inadequate 'tick box' forms of engagement as academics and clinicians engage with members of the public with little commitment to the user involvement agenda. This can result in dissatisfactory experiences of user involvement for both users and academics alike. Hence, difficulties associated with involving users may be the result of inadequate processes of engagement rather than anything problematic with user involvement itself.

Users can be involved throughout the research process, from identifying topics, designing studies, collecting and analyzing data, to disseminating findings [9]. However, users are typically invited to comment on information sheets or sit on steering committees only. Although this form of engagement is important, the benefits of involving users in more developed ways, such as data collection and analysis, must be recognized. The Macmillan Listening Study [14] provides an example of a more sophisticated approach to user involvement [14].

The Macmillan Listening Study was the first UK public consultation exercise to be conducted concerning priorities for research. The study involved a series of 17 consultation groups including 105 patients. Patients were purposively sampled to ensure a mix in terms of sex, cancer type, age, ethnicity, stage of treatment and involvement in research [1]. The top priority for research identified by study participants was research into the 'Impact of life, how to live with cancer and related support issues'. This theme was subdivided into nine areas, including psychological consequences, self-help groups, follow up and after-care, impact on social functioning, 
Table 1

Top priority areas in the Macmillan Listening Study

\begin{tabular}{lll}
\hline Research priority & Subtheme & Subsubtheme \\
\hline $\begin{array}{l}\text { Impact on life, how to live with cancer } \\
\text { and related support issues }\end{array}$ & Psychological consequences & $\begin{array}{l}\text { Impact on patient and others } \\
\text { Role of mental attitude in recovery } \\
\text { Support mechanisms }\end{array}$ \\
& Self-help groups and peer support & $\begin{array}{l}\text { Impact of support groups } \\
\text { How to establish or access groups }\end{array}$ \\
& Follow up and after-care & $\begin{array}{l}\text { Impact of after-care } \\
\text { General }\end{array}$ \\
& Impact on social functioning & - \\
& Work and other financial impacts & Employment issues \\
& Financial consequences \\
& Pain management & - \\
Impact on family and others & Diet in managing cancer & - \\
\hline
\end{tabular}

Data from Corner and coworkers [1].

work and financial issues, pain management, impact on family and others, diet and general lifestyle factors in managing cancer (Table 1) [1].

Comparing these findings with health professional priorities reveals key differences. Research prioritization studies involving health care professionals often identify the design and co-ordination of research, research into the biological effects of treatment, symptom management, and service delivery and organization issues as areas of high priority $[15,16]$. These were not reflected in the top priority areas of the Macmillan Listening Study. Conversely, priorities identified by the Study participants, such as research into self-management activities and the impact of cancer on dayto-day lives, are not commonly determined by health care professionals. The priority of communication illustrates the differences between health care professional and user priorities. Although communication skills and breaking of bad news by health care professionals have been identified by clinicians as important areas for research and have been extensively researched [15], participants in the Macmillan Listening Study were also interested in how patients can communicate their diagnosis and treatment with partners, family members and others close to them. This area of research has received less attention [14]. Consequently, findings from the Macmillan Listening Study suggest that the scope of cancer research activity should be greater to reflect a broad spectrum of interests, including those of people affected by the disease.

\section{Conclusion}

The Macmillan Listening Study illustrates the important role that users can have in research. The study reveals the need to involve users in considerations about the research agenda, particularly because their views may differ from those of clinicians. Failure to involve users in prioritizing topics for research can result in important areas of inquiry being undersupported.

Reflecting on user involvement more broadly, it is important to note that, regardless of personal opinion, user involvement is firmly established as a necessary facet of health research. Although it is recognized that certain types of research, such as psychosocial studies, lend themselves to more creative forms of engagement, it must also be appreciated that there is always scope for user involvement. For user involvement to be successful, it must be regarded as an important part of the research process and not a superficial 'tick-box' exercise. Real engagement requires careful consideration, planning and application. Researchers fail to do this all too often, resulting in difficulties that are erroneously attributed to the user rather than the process through which they have been involved.

\section{Acknowledgements}

The Macmillan Listening Study was initiated and funded by Macmillan Cancer Support.

This article has been published as part of Breast Cancer Research Volume 9 Supplement 2, 2007: Controversies in Breast Cancer. The full contents of the supplement are available online at http://breastcancer-research.com/supplements/9/S2.

\section{References}

1. Corner J, Wright D, Hopkinson J, Gunaratnam Y, McDonald JW, Foster C: The research priorities of patients attending UK cancer treatment centres: findings from a modified nominal group study. Br J Cancer 2007, 96:875-881. 
2. Department of Health: Research Governance Framework, 2nd edn. London, UK: Department of Health; 2005.

3. Wright D, Corner J, Hopkinson J, Foster C: Listening to the views of people affected by cancer about cancer research: an example of participatory research in setting the cancer research agenda. Health Expect 2006, 9:3-12.

4. Chambers R, O'Brien LM, Linnell S, Sharp S: Why don't health researchers report consumer involvement? Qual Prim Care 2004, 12:151-157.

5. Anderson W, Gillam S: The elusive NHS consumer: 1948 to the NHS Plan. Economic Affairs 2001, December:14-18.

6. Mort M, Wiston G: The user card: picking through the organisational undergrowth in health and social care. Contemporary Political Studies 1996, 2:1133-1140.

7. Reason $\mathrm{P}$, Bradbury H (editors): Introduction: inquiry and participation in search of a world worthy of human aspiration. In Handbook of Action Research: Participative Inquiry and Practice. London, UK: Sage; 2001:1-14.

8. Park P: People, knowledge, and change in participatory research. Management Learning 1999, 30:141-157.

9. Hanley B, Bradburn J, Barnes M, Evans C, Goodare H, Kelson M, Kent A, Oliver S, Thomas S, Wallcraft J: Involving the Public in
NHS, Public Health, and Social Care Research: Briefing Notes for Researchers, 2nd ed. Eastleigh, UK: INVOLVE; 2003.

10. Katbamna S: Experiences and Needs of Carers from South Asian Communities. Leicester, UK: Nuffield Community Care Studies Group, University of Leicester; 1997.

11. Stevens T, Wilde D, Hunt J, Ahmedzai SH: Overcoming the challenges to consumer involvement in cancer research. Health Expect 2003, 6:81-88.

12. Truman $C$, Raine $P$ : Involving users in evaluation: the social relations of user participation in health research. Crit Public Health 2001, 11:215-229.

13. Involve: Promoting Public Involvement in NHS, Public Health and Social Care Research [http://www.invo.org.uk/]

14. Corner J, Wright D, Foster C, Gunaratnam Y, Hopkinson J Okamoto I: The Macmillan Listening Study: Listening to the Views of People Affected by Cancer about Cancer Research. Published Report. London, UK: Macmillan Cancer Support; 2006.

15. Bakker DA, Fitch Ml: Oncology nursing research priorities: a Canadian perspective. Cancer Nurs 1998, 21:394-401.

16. Stetz KM, Haberman MR, Holcombe J, Jones LS: 1994 Oncology Nursing Society Research Priorities Survey. Oncol Nurs Forum 1995, 22:785-789. 